\title{
Interactions between sediment propagule banks and sediment nutrient fluxes explain floating plant dominance in stagnant shallow waters
}

\author{
Ger Boedeltje, Alfons J. P. Smolders, Leon P. M. Lamers and \\ Jan G. M. Roelofs ${ }^{1}$
}

Radboud University Nijmegen, Department of Ecology, Research group of Aquatic Ecology and Environmental Biology

With 1 figure and 2 tables

\begin{abstract}
Mats of floating plants are known to have detrimental effects on aquatic life as they reduce the penetration of light so that submerged species are unable to develop. These mats also prevent gaseous exchange between water and atmosphere resulting in anoxic conditions of the water layer. In shallow waters, nutrient fluxes from the sediment to the water layer are expected to play a key role in the shift to floating plant dominance. This study investigated the potential recruitment and development of duckweed mats from propagule banks in field enclosures containing either muddy or sandy sediment. It was observed that free-floating fronds of Lemna minor were derived from both sediment types, but that dense duckweed mats developed exclusively in enclosures with muddy sediment. The results can be explained by differences in nutrient release from the sediments to the overlying water during summer, when high fluxes, especially of phosphorus and nitrogen, were observed almost exclusively in enclosures with muddy sediment involving anoxia of the water layer. This study discusses the results in relation to free-floating plant dominance and the management of shallow waters.
\end{abstract}

Key words: anoxia, duckweed, eutrophication, Lemna minor, nitrogen flux, phosphorus flux, seed bank, stable state.

\section{Introduction}

Mats of floating plants including duckweeds (Lemnaceae) are known to have detrimental effects on aquatic life. The penetration of light is strongly reduced

1 Authors' address: Radboud University Nijmegen, Department of Ecology, Research Group of Aquatic Ecology and Environmental Biology, Toernooiveld 1, 6525 ED Nijmegen, The Netherlands; E-mail: G.Boedeltje@ science.ru.nl 